\title{
Assessment of the Conditions that Determine the Reclaiming of Stone Materials and their Use in the Revalorisation of Historical Buildings
}

\author{
Elżbieta Radziszewska-Zielina ${ }^{1, *}$, Grzegorz Śladowski ${ }^{2}$ \\ ${ }^{1,2}$ Cracow University of Technology, Faculty of Civil Engineering, Institute of Management in \\ Construction and Transport, Chair of the Technology and Organization of Construction
}

\begin{abstract}
The paper focuses on the problem of the effective management of materials obtained from demolition in the scope of the revalorisation of historical structures. The conditions that influence the reclamation and reuse of materials were analysed. The entirety of the discussion was based on the practical example of the revalorisation of the Outer Courtyard of Wawel Castle, for which the importance of these conditions has been determined, as well as the relationships between them.
\end{abstract}

\section{Introduction}

Renovation work and demolition work belong to the group of construction works that generate larger amounts of waste than in the case of erecting new structures. In such cases, appropriate waste management, which needs to be taken into account already at the planning and design stage, and needs to be implemented during the carrying out of a project, is of particular importance [1]. Examples of good practice of such an approach can be found in literature [2-5]. Within the scope of these processes, physical flows of waste occur, which need to be carried out in accordance with the principles of reverse logistics $[6,7]$. The implementation of the principles of reverse logistics should be preceded by an analysis of the conditions related to a given project.

An interpretation of the fundamental conditions associated with the recycling of materials during renovation projects can be found in literature [8].

The goal of this article is the broadening of this set of conditions for the purposes of analysing the problem of recycling in projects associated with the revalorisation of historical buildings. In addition, an analysis of the impact of these conditions and the relations between them - in relation to the project of the revalorisation of the Outer Courtyard of Wawel Castle - has been performed.

\section{The conditions that determine material reclamation and reuse in the scope of the revalorisation of historical buildings}

Environmental protection conditions require us to respect the regulations contained in the Waste Act of the 14th of December 2012 [9]. In it are "defined the means that serve the protection of the environment, life and health of people, the prevention and lessening of negative influence on the environment and human health resulting from the production of waste and its management, as well as the limitation of the overall effects of the use of resources and the improvement of the effectiveness of said use". The manner of planning,

*Corresponding author: eradzisz@ztob.pk.edu.pl 
design and performing of work, including construction work, should include first and foremost the prevention of the production of waste and, in the case of its occurrence, the preparation of materials for reuse. The recycling of materials or other reclamation processes should be considered next, with neutralisation being the final option. In accordance with the "principle of proximity" provided in the Act, we should first strive to process waste on the site of its production (on the construction site).

Technical conditions associated with the evaluation of the physical, chemical, mechanical and aesthetic parameters of the materials obtained through demolition in terms of their reuse within a structure. Many tools and diagnostic methods are currently available: ones based on, for instance, electromagnetic or acoustic procedures, which can constitute an alternative to the typical destructive methods. Whether a piece of material is going to be cleared for reuse depends on the meeting of quality criteria outlined in the technical documentation.

Architectural conservation conditions associated with conservational requirements, determined individually for each project involving the performing of work on a historical building or within the surroundings of one. The basic goal of conservation authorities is the securing and preservation of original historical substance, which is why there is a tendency to minimise demolition work on elements of historical structures to a minimum and to reclaim and reuse as much material that is of historical value as possible.

Financial conditions apply to the technology and organisation of work in the context of the reclamation of construction materials and their reuse through reincorporation. These conditions apply to the financial costs of the performance of: construction work, the transport of materials obtained through demolition, the necessary quality analysis, as well as work that prepares an element for reincorporation or its recycling and neutralisation.

Temporal conditions associated with the time needed for performing the abovementioned technological and organisational processes in the context of the reclamation of construction materials and their reincorporation, or recycling, as well as neutralisation.

\section{The proposed approach to the evaluation of the importance of conditions and the relationships between them}

The analysis of the conditions described above indicates that their descriptions mutually overlap, which justifies the necessity to include interdependency in their analysis, including so-called feedback loops between them. As a result, this train of thought leads us to establish a network structure of the relations between the conditions. The ideological scheme of the proposed network structure is presented on (figure 1).

The notion of a system as an object composed of various elements, between which there are certain relations (dependencies) [18] lies at the foundation of numerous methods used in the analysis of various problems of an inter-dimensional character, for instance [10-17]. In order to synthetically describe and analyse the dependencies above, it is necessary to select an appropriate tool which will allow us to properly model and analyse the dependencies between the elements of the system in question.

One of the effective concepts of the replication of such a system is structural modelling, understood as a set of diverse techniques which make it possible to understand the properties of complicated systems [19].

Many structural modeling methods can be found in the literaturę [20,21]. Recently a method has also been developed WINGS method (Weighted Influence Non-linear Gauge System) [22]. 


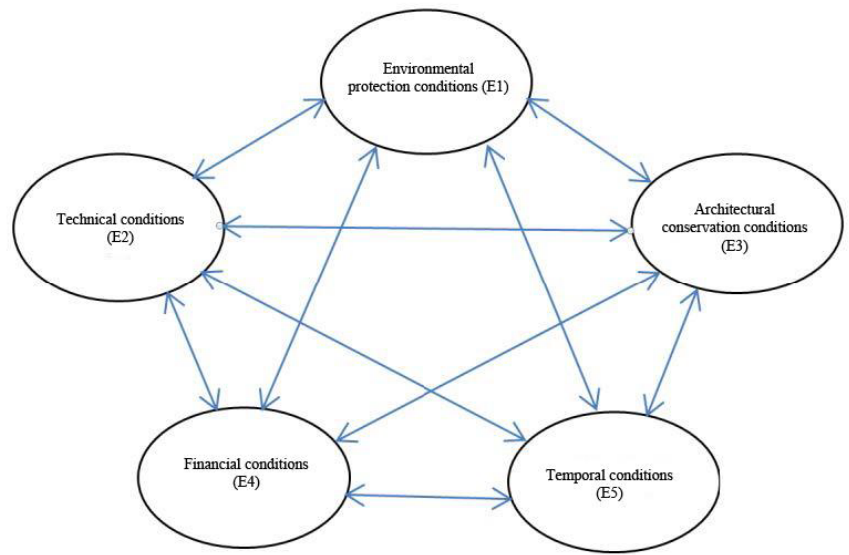

Fig. 1. Ideological scheme of the network structure of the relationships between the elements of the analysed system. Source: original work

In these methods, the tool used to model the dependencies between the elements of the system is a directed graph, the tips of which symbolise the elements of the system and the arches determine the relations (mutual influence between the elements of the system).

The evaluation of the impact of the elements and the intensity of the influence between these elements is performed by an expert with the help of a four-point verbal scale, to which numerical values have been assigned. The input values of evaluations are introduced into a matrix, the sum of all the powers of which, in the liminal sense, returns the output values in the analysed model.

The effect of the use of the WINGS method is the determining of the value of total impact $\left(r_{i}\right)$ of the system's $i$ element, as well as its total susceptibility $\left(c_{i}\right)$.

The sum of the values of $\left(r_{i}\right)$ and $\left(c_{i}\right)$ determine the total involvement of element $i$, while their difference informs us of the role of the element in the system. A positive value of the difference $\left(r_{i}-c_{i}\right)$ states that element $i$ constitutes a cause, while a negative value labels it an effect within the analysed system. The absolute value of the difference $\left(r_{i}-c_{i}\right)$ determines the strength of the abovementioned causal (effectual) character of the element under discussion.

In order to make the analysis of the relations between the elements of the analysed system easier, the values that are obtained can be depicted in a graphical form on a twodimensional set of coordinates, forming a so-called impact-relation map - IRM. The values of the difference $\left(r_{i}-c_{i}\right)$ are placed on the axis of ordinates, while the values of the sum $\left(r_{i}+c_{i}\right)$ are placed along the abscissa.

\section{Case study}

\subsection{Basic information on the project}

In order to present the proposed systemic approach to the evaluation of the impact of and the relations between the conditions that determine the reuse of materials obtained through dismantlement, the authors used the example of the revalorisation of the Outer Courtyard of the Wawel Castle, see fig. 2.

The main element of the project in question was the comprehensive replacement of paved surfaces (around $10000 \mathrm{~m}^{2}$ ) along with the redevelopment of external stairs and the construction of a driveway and a ramp for disabled persons. The revalorisation work was an 
activity that was sorely needed due to the worsening technical condition of the stone surfaces of the Outer Courtyard, the driveways, as well as the poor condition of the underground infrastructure (water pipes, sewerage, power cables, fire safety infrastructure and telecommunications).

The recreation and improvement of the condition of immobile historical artefacts, as well as increasing the quality level of services for domestic and foreign tourists as a part of the popularisation of global cultural heritage allowed the project to be qualified for the "Priority XI Operational Programme Infrastructure and the Environment, action 11.1 "The protection and preservation of cultural heritage of supralocal importance".

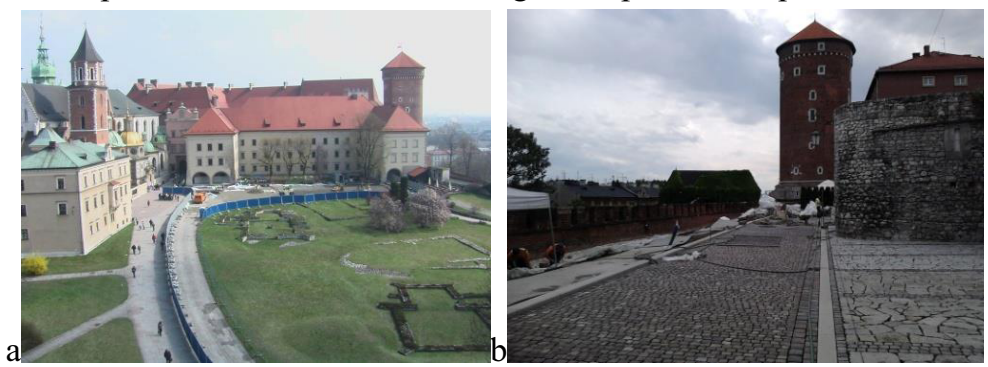

Fig. 2. a) The Outer Courtyard during revalorisation, b) Wawel Hill parking lot surfaces

\subsection{Structural analysis of the conditions}

The description of the conditions for the project in question is as follows:

\section{Environment protection conditions (E1)}

The specifics of the project have, to a large degree, made it possible to achieve the goals outlined in the act of law. The strategy of achieving the maximum possible reclamation and reincorporation of the materials obtained through dismantlement and recycling, as well as the neutralisation of produced waste, constituted the achievement of the basic goals of the project. However, due to the specific nature of the site and the difficulties associated with, among other things, the lack of sufficient space for storing the reclaimed materials, the "principle of proximity" could not be followed during their processing. All of the processes associated with the evaluation and adaptation of the materials for reuse or recycling and processing took place in an area located a couple of kilometres away from the construction site, see fig. 3 .

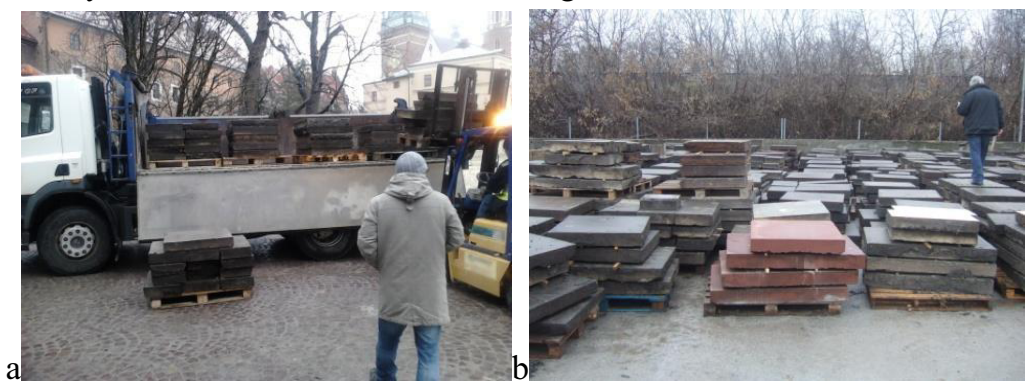

Fig. 3. a) Loading the stone elements on a lorry, b) The storage area away from the construction site, where the stone elements were kept

\section{Technical conditions (E2)}

The evaluation of the technical condition of the stone elements obtained through dismantlement was performed primarily on the basis of an initial inspection of the elements 
in order to eliminate those which showed signs of cracking or delamination, see fig. 4a. Samples were taken for each batch of elements in order to perform laboratory analyses and determine the compatibility of the physical, chemical and mechanical properties of the analysed materials with the requirements outlined in the design. Over the course of the analysis it turned out that the existing sandstone tiles did not meet the requirements outlined in the design regarding compressive strength, despite having high parameter values. However, taking into account the fact that the remaining qualities that were analysed did meet the requirements of the design, including tensile strength (in the case of large tiles this parameter is more important than compressive strength) and, in the face of a high reclamation rate approaching $50 \%$, the designer approved the sandstone tiles in question to be reincorporated by request of the property owner and the conservator, as well as on the basis of an expertise, see fig. $4 \mathrm{~b}$. Rejecting such materials would have been a case of farreaching wastefulness and mismanagement.
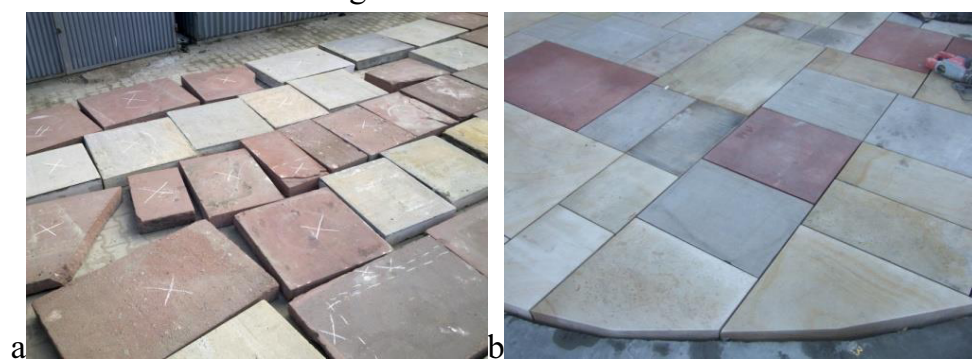

Fig. 4. a) Initial selection of sandstone tiles for reuse, b) The reclaimed tiles composed with new tiles

\section{Architectural conservation conditions (E3)}

The Wawel Hill is a listed site, which is why, at the behest of the conservator, the condition of the maximum possible reclamation of stone materials obtained through dismantlement was introduced. The "arched" layout of the sandstone tiles suggested by the conservator, including the mixing of original tiles with new ones, as well as the running pattern of porphyry cobblestone, determined additional procedures associated with the cleaning, proper processing and cutting of the reclaimed tiles before their reincorporation. In addition, a part of the existing sandstone tiles was cut and used as cobblestone, see fig. $5 \mathrm{a}$, or as tiles with irregular shapes and sizes, see fig. $5 \mathrm{~b}$.
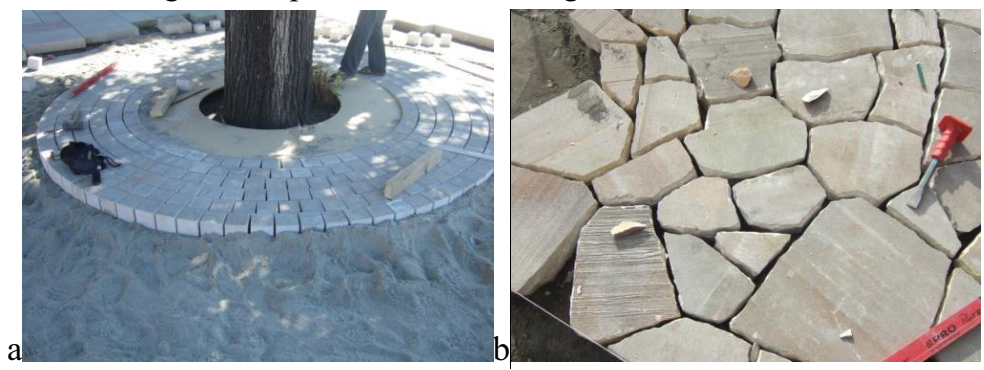

Fig. 5. a) The laying of cobblestone obtained from the cutting up of existing reclaimed tiles, b) Laying leftover elements from cutting sandstone tiles.

\section{Financial conditions (4)}

Due to the specifics of the location and the performing of the work on a so-called active property (unlimited access by tourists and the employees of Wawel Hill), all technological and organisational processes generated high costs. These costs were associated with: dismantlement work, the initial stocktaking of the elements and their transport to the storage area, the performance of costly quality analyses and processing, transport to the 
construction site and, in the case of producing waste - its processing. Due to the multi-stage structure of the project, all logistics activities were based on cyclically developed designs for each stage: the organisation of the site and traffic management, which was not without impact on the costs.

\section{Temporal conditions (E5)}

The costs of the duration of the completion of the project, similarly to the general costs of the project, were associated with the aforementioned technological and organisational processes. A lot of time needed to be dedicated to the quality analyses of the reclaimed stone elements, and, in particular, the recreation of 48 cycles of freezing and thawing during the process of assessing the frost resistance of these elements. Under the conditions of limited required completion time for each stage of the work, the above-mentioned technological and organisational process, including the time-consuming material analysis, required the development of detailed project schedules.

Using the aforementioned systemic approach and the WINGS procedure (Weighted Influence Non-linear Gauge System), an expert evaluated the significance of each condition (the elements of the system) in a linguistic manner (using an evaluation scale, presented in table1, that had been developed for the purposes of this method), as well as their direct influence and its intensity, see table 2.

Table 1. Linguistic evaluations of the importance and influence of an element and their representation in on a four point scale

\begin{tabular}{|c|c|c|c|}
\hline \multicolumn{2}{|c|}{$\begin{array}{c}\text { Assessing the significance of an element in } \\
\text { the system }\end{array}$} & $\begin{array}{c}\text { Assessing the influence of an element } \\
\text { in the system }\end{array}$ \\
\hline Linguistic assessment & $\begin{array}{l}\text { Point } \\
\text { scale }\end{array}$ & Linguistic assessment & $\begin{array}{c}\text { Point } \\
\text { scale }\end{array}$ \\
\hline No significance (NS) & $(0)$ & No influence (NI) & $(0)$ \\
Low significance (LS) & $(1)$ & Low influence (LI) & $(1)$ \\
Average significance (AS) & $(2)$ & Average influence (AI) & $(2)$ \\
High significance (HS) & $(3)$ & High influence (HI) & $(3)$ \\
Very high significance (VHS) & $(4)$ & Very high influence (VHI) & $(4)$ \\
\hline
\end{tabular}

Table 2. Linguistic assessments of the significance and the mutual, direct influence of the system's elements and its intensity

\begin{tabular}{|c|c|c|c|c|c|}
\hline $\begin{array}{c}\text { Elements of the } \\
\text { system }\end{array}$ & E1 & E2 & E3 & E4 & E5 \\
\hline E1 & HS & HI & AI & VHI & VHI \\
\hline E2 & LI & VHS & AI & HI & HI \\
\hline E3 & HI & VHI & VHS & VHI & VHI \\
\hline E4 & AI & AI & LI & HS & LI \\
\hline E5 & AI & AI & LI & AI & AS \\
\hline
\end{tabular}

As a consequence, the process of algebraic conversions, while taking into account indirect relations, has produced the values of the total significance and the influence between the elements of the system in question. As a result, the total impact values have been determined for element $i$, as well as its total susceptibility. Figure 6 illustrates the impact-relation map for the analysed elements of the system. 


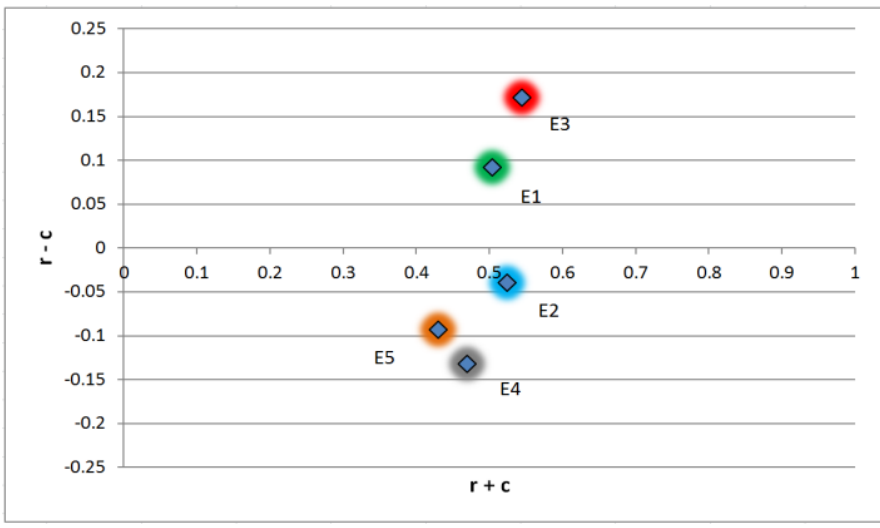

Fig. 6. The impact-relation map of the elements of the system

\subsection{Analysis of the results}

The total involvement values $\left(r_{i}+c_{i}\right)$ determine the ranking of the elements within the system. For the case under analysis, the value $\left(r_{i}+c_{i}\right)$ is the highest for architectural conservation conditions (E3) (fig.2). In addition, the highest positive value of the relations parameter $\left(r_{i}-c_{i}\right)$ that has been obtained for this parameter is evidence of its strong impact on the remaining elements of the system. Technical conditions (E2) placed second in terms of total involvement, however, the negative value of $\left(r_{i}-c_{i}\right)$ indicates that this element is susceptible to influence exerted by architectural conservation conditions (E3), as well as the conditions of environmental protection (E1). This is because the role of condition (E1), similarly to (E3), due to their positive $\left(r_{i}-c_{i}\right)$ values, has a character that impacts other elements within the system. The subsequent places within the ranking of the conditions in terms of total involvement, are, respectively, occupied by the conditions associated with environmental protection (E1), as well as cthe onditions associated with costs (E4) and temporal conditions (E5). However, despite the fact that temporal conditions (E5) placed last, they are less susceptible to influence within the system than element (E4).

\section{Conclusions}

The implementation of the principles of reverse logistics within a given construction project should be preceded by an analysis of its conditions, the type and character of which is going to depend on its specifics. Expanding the set of basic conditions that are known from literature [8] by including additional ones will allow a comprehensive analysis of the problem in question to be performed in the scope of projects associated with the revalorisation of historical buildings. The paper contains the proposal of a systemic approach to the evaluation of these conditions, while taking into account the interdependencies between them. The entirety of the discussion has been backed by a practical example of the evaluation of the conditions that determined the reclamation process and the reuse of materials during the revalorisation of the Outer Courtyard at Wawel Hill. In the future, the degree of subjectivity can be reduced in the proposed approach to the assessment of conditions by introducing the formulation of evaluations by a group of experts, as well as elements of fuzzy logic due to the uncertainty of the opinions that will be formulated [23]. The evaluation of the impact and relations of these conditions can be helpful in defining the acceptable variants of construction waste management within the scope of construction projects in the future, particularly concerning the revalorisation of historical buildings. 


\section{References}

1. A. Sobotka, J. Czaja, Procedia Engineering 122 (Orsdce) (2015)

2. A. Sobotka, J. Sagan, A. Sikora, Materiały Budowlane 526(6) (2016)

3. J. Czaja, M. Szczygielski, Ł Stopa, M. Blajer, Logistyka 4 (2015)

4. A. Sobotka, J. Sagan, The World Multidisciplinary Civil Engineering-ArchitectureUrban Planning Symposium, June, Prague (2016)

5. J. Czaja, J. Jaskowska-Lemańska, D. Wałach, Logistyka 4 (2015)

6. J. Czaja, A. Sobotka, Logistyka 2 (2015)

7. J. Sagan, A. Sobotka, Builder (2016)

8. J. Sagan, A. Sobotka, Inżynier Budownictwa 12 (2016)

9. Ustawa z dnia 14.12.2012 o odpadach. Dz.U. 2013 p. 21

10. N. Ibadov, J. Rosłon, ACE 61(3) (2015)

11. MV Ksiażek, P. Nowak, S. Kivrak, JH, Roslon, L. Ustinovichius, Journal of Civil Engineering and Management 21(2) (2015)

12. E. Radziszewska-Zielina, B. Szewczyk, ACE 1(3) (2015)

13. Radziszewska-Zielina E., The Application of Multi-Criteria Analysis in the Evaluation of Partnering Relations and the Selection of a Construction Company for the Purposes of Cooperation, „Archives of Civil Engineering”, 2(62) (2016)

14. Radziszewska-Zielina E., Szewczyk B., WMCAUS 2016, Procedia Engineering 2(62) (2016)

15. Krzemiński, M., ACE 2(62) (2016)

16. Radziszewska-Zielina E., Rumin R., SEED 2016, E3S Web Of Conferences 10 (2016)

17. Korytarova J., Hanak T., Kozik R., Radziszewska-Zielina E., Procedia Engineering 123 (2015)

18. J. Michnik, Wielokryterialne metody wspomagania decyzji $w$ procesie innowacji (Uniwersytet Ekonomiczny w Katowicach, Katowice, 2013)

19. F.S. Roberts, Journal of Mathematical Psychology 3 (29) (1985)

20. T. L. Saaty, Decision Making with Dependence and Feedback, The Analytic Network Process (University of Pittsburgh, RWS Publications, 1996)

21. A. Gabus, E. Fontela, World Problems an Invitation to Further Thought within the Framework of DEMATEL (Battelle Geneva Research Centre, Switzerland Geneva, 1972)

22. J. Michnik, European Journal of Operational Research 228 (2013)

23. E. Radziszewska-Zielina, G. Śladowski, Journal of Cultural Heritage (2017), https://doi.org/10.1016/j.culher.2017.02.008

24. B. Jankowski, J. Prokocki, M. Krzemiński, Procedia Engineering 111, 351-355 (2015)

25. M. Krzemiński, Acta Physica Polonica A, 130(6), 1439-1442 (2016)

26. M. Kaftanowicz, M. Krzemiński, Procedia Engineering, 111, 364-370 (2015) 